\title{
REGINA PAHIM PINTO IN MEMORIAM
}

Regina Pahim Pinto, nossa colega do Departamento de Pesquisas Educacionais - DPE - da Fundação Carlos Chagas - FCC - desde 1977, faleceu no dia 22 de abril deste ano de 2010 , alguns dias depois de completar 69 anos, em decorrência de uma doença autoimune rara. "Perda inestimável para a pesquisa e o ativismo na luta por uma educação brasileira antirracista" foi o teor unânime das mensagens que recebemos de colegas de várias partes do Brasil e de aprendizes pesquisadores(as) que integram o Programa Internacional de Bolsas de Pós-Graduação da Fundação Ford - IFP -, no qual Regina participava da Equipe de Coordenação.

Conheci a Regina, em outubro de 200 I, quando me apresentei na Fundação Carlos Chagas para uma reunião com o grupo formado pela Fúlvia, pela Maria e por ela. Grupo este que acabava de assumir o desafio de implantar, no Brasil, o Programa Internacional de Bolsas de Pós-Graduação da Fundação Ford, "popularmente" conhecido como Programabolsa. Atendia a um convite para participar da equipe. Em virtude do aceite do convite, pude conviver com a Regina por 8 anos. Tempo suficiente para testemunhar a sua competência profissional. Admirava muito seu interesse e responsabilidade, quando do desempenho de todas as funções e tarefas que assumiu neste processo. O reconhecido sucesso do Programabolsa, certamente, deve muito a ela.

Maria Luisa Santos Ribeiro (IFP - Equipe de coordenação)

Convivi com a Regina quase que ininterruptamente nesses 33 anos de sua trajetória no DPE. Fomos parceiras de várias pesquisas tratando de temas relacionados à educação, infância, gênero e relações étnico-raciais. Publicamos juntas vários artigos e alguns livros. Éramos velhas companheiras, tínhamos cacoetes de relacionamento como aqueles que aparecem na convivência de antigos casais. Quando não a encontro em nossa sala, minha sensação é que Regina está de férias e que logo, logo voltará para assumir a coordenação de seu último e inovador trabalho junto ao Programa de Bolsas IFP: organização da Série Justiça e Desenvolvimento IFP/FCC, composta por coletâneas temáticas 
que integram artigos de ex-bolsistas IFP. Nesta atividade, Regina era incansável, precisa e... exigente. Quando, já fragilizada, Ihe perguntávamos se não seria melhor tirar licença médica, respondia-nos que este trabalho era um pedaço de vida em suas aflições.

Uma perda enorme. Tive o prazer de conviver com Regina durante a edição de nosso livro Ambiente complexo, proposta e perspectivas socioambientais.

Paulo Moutinho

(Instituto de Pesquisa Ambiental da Amazônia - Ipam)

Trabalhei tanto e animadamente com a Regina no ano passado para a edição de nosso livro conjunto Acesso aos direitos sociais: infância, saúde, educação, trabalho. Que triste!

Paulo Sérgio Pinheiro

(Núcleo de Estudos da Violência/Universidade de São Paulo)

Perdemos um grande nome da luta contra o racismo no país, perdemos uma profissional espetacularmente dedicada a tudo que fazia, incansável revisora dos nossos escritos. Tivemos pouco contato, mas foi o bastante para desenvolver admiração e respeito por ela.

Ilzver Matos

(ex-bolsista IFP)

Regina, socióloga de formação, cursou o mestrado e o doutorado na Universidade de São Paulo - USP. Aparecida Joly Gouveia foi sua orientadora na dissertação de mestrado em Sociologia - O livro didático e a democratização da escola (1977) - modelo de pesquisa rigorosa até hoje. $\bigcirc$ doutorado em Antropologia Política - O movimento negro em São Paulo: luta e identidade ( 1993 ) - , orientado por João Baptista Borges Pereira, é um marco.

A professora Regina Pahim era uma intelectual incrivel. Aprendi muito com seus artigos e sua tese de doutorado. Lembro da emoção de conhecê-la e de seus conselhos para minha pós-graduação, tão valiosos que os guardo comigo com grande carinho. Lembro, também, de seu auxílio para a minha 
dissertação, doando o material que utilizou em sua tese sobre a Frente Negra Brasileira e que está num lugar especial em minha biblioteca. É uma grande perda para a luta contra as desigualdades étnico-raciais e de gênero e para a educação brasileira. Sua obra viva permanecerá iluminando os nossos caminhos na guerra sem fim contra o racismo.

Carlos Eduardo Dias Machado (ex-bolsista IFP)

Regina Pahim deu uma grande contribuição aos estudos da população negra/mestiça no Brasil, ao realizar um doutorado em Antropologia na USP versando sobre a Frente Negra Brasileira (um valioso "catatau" nunca publicado em livro). Sua tese foi responsável por uma retomada dos estudos sobre a população negra, olhando de forma crítica e resgatando o legado teórico de Roger Bastide, Florestan Fernandes e seus orientandos (grupo conhecido no meio acadêmico como Escola Paulista de Sociologia).

Marcio Macedo (bolsista IFP)

Apesar de ter realizado pesquisas e publicado em vários campos de conhecimento - gênero, educação infantil, educação básica e formação professores -, o tema das relações étnico-raciais foi o que mereceu a maior parte de sua atenção, tanto do ponto de vista da quantidade, quanto da qualidade: Regina atribuiu suas estrelas no Currículo Lattes (última atualização em 2005), todas para suas publicações na temática das relações raciais. Típico da Regina: indicou apenas quatro estrelas em suas publicações. Foram elas:

PINTO, R. P. Educação do negro: uma revisão da bibliografia. Cadernos de Pesquisa, São Paulo, n.62, p. 3-34, 1987.

PINTO, R. P. A Escola e a questão da pluralidade étnica. Cadernos de Pesquisa, São Paulo, n.55, p. 3-17, 1985.

PINTO, R. P. A Formação do professor e a diversidade étnico-racial. In: REUNIÃO ANUAL DA ANPEd, 22. Caxambu, 1999.

ROSEMBERG, F.; PINTO, R. P.; PIZA, E.; OLIVEIRA, E. A Classificação de cor no Brasil: impasses e perspectivas. In: ENCONTRO ANUAL DA ANPOCS, 19. Programa e resumos. São Paulo: Anpocs, 1995. p. |44- 145. 
Vocês não sabem o quanto lamento a partida da Regina. Ela foi uma das primeiras autoras que li sobre relações raciais e educação, no número do Cadernos de Pesquisa organizado em 1987 (Raça Negra e Educação). Depois, tive a oportunidade de conhecê-la na Anped, me surpreendeu seu trato afável - às vezes tão raro na academia -, sua modéstia e sua grande competência e rigor como pesquisadora. Acho que é uma perda irreparável para a pesquisa em Educação.

Maria Lúcia Rodrigues Müller (Universidade Federal do Mato Grosso)

Comungando com o sentimento de todos, quero expressar meu pesar pelo falecimento de Regina, de quem guardo gratas lembranças de nossas discussões ao redor de nossos temas próximos de estudo, quando, nos anos oitenta, fazendo meu curso de doutorado no luperj participava, como ela, do GT da Anpocs sobre questão racial.

Maria Angélica Maués (Universidade Federal do Pará)

Regina participou ativamente do projeto da Associação Nacional de Pesquisa em Educação - Anped -, Concurso Negro e Educação, quando trabaIhou em colaboração estreita, entre outros(as), com as professoras Petronilha Beatriz Gonçalves Silva, Iolanda de Oliveira e Maria Clara di Pierro.

Conheci Regina logo que reingressei na pós-graduação de Sociologia da USP, nos anos setenta. Tínhamos a mesma orientadora, a Professora Aparecida Joly Gouveia. Participamos de grupos de estudo e de preparação de seminários juntas, sendo alguns deles na casa de Regina, no bairro Alto de Pinheiros, no meio de cachorros, gatos e plantas.

Depois, nos tornamos colegas também na Fundação Carlos Chagas, quando participamos de projetos na área que então era chamada de estudos sobre a mulher. Desde esse tempo, que já vai distante, estivemos juntas em projetos, de forma intermitente: ora eu participava de algo em que ela já estava inserida antes, ora acontecia o inverso. Nossa pessoa de ligação sempre foi Fúlvia Rosemberg, coordenadora de muitos desses projetos.

Nos últimos anos, fomos parceiras em um programa de ação afirmativa, 
o Programabolsa da Fundação Ford, sediado em nossa instituição. Mas, antes disso, Regina desempenhou também um papel muito importante no Programa Negro e Educação, sediado na Ação Educativa e promovido pela Anped. A igualdade racial e da luta contra a discriminação haviam se tornado o seu tema e, no Programabolsa, seu compromisso com a causa do negro transbordou para os povos indígenas do Brasil, sempre de acordo com seu peculiar estilo de atuar, que aliava simplicidade com aguda capacidade crítica.

Regina não deixa somente saudades, mas um lugar vazio nesse campo de trabalho, que ganhou importância crescente no país devido, inclusive, à sua própria dedicação e competência.

Maria Malta Campos (Pesquisadora FCC)

Para quem não se lembra ou não sabe, Regina, que trabalhou por longo tempo na Fundação Carlos Chagas, foi - junto com a professora Petronilha Beatriz Gonçalves Silva - membro do comitê coordenador do Concurso Negro e Educação em pelo menos duas de suas edições, quando a secretaria do Concurso esteve ao nosso encargo, em Ação Educativa. Assim, Orlando, Suelaine e eu trabalhamos bastante com ela, e foi com grande tristeza que recebi a notícia de sua morte. No seu enterro, no Cemitério do Araçá, descobri que fui, no início da carreira, professora da sua filha. Assim, vamos tomando consciência da nossa posição no ciclo da vida.

Maria Clara Di Pierro (USP e Ação Educativa)

Sinto muitas saudades do período em que vivi com a Regina, aquele jeito DELA muito particular, exigente e muito rigorosa em todas as SUAS atividades... E eu que tinha esperança de conviver com ELA novamente...??!!!!

lolanda de Oliveira (Universidade Federal Fluminense)

Regina e eu compartilhamos a editoria de Cadernos de Pesquisa por vários anos, além do que, trabalhamos juntas em alguns projetos de 
pesquisa na Fundação Carlos Chagas e fomos assíduas participantes do Grupo de Estudos Educação e Sociedade da Associação Nacional de PósGraduação e Pesquisa em Ciências Sociais - Anpocs - nos anos iniciais de sua criação.

Com ela podíamos sempre contar nas aflições de trabalho, nas ocasiões em que precisávamos correr contra o tempo para fechar a revista sem perder a periodicidade, na edição de textos trôpegos que ela tinha prazer em tornar mais agradáveis ao leitor.

Várias vezes se dispôs a falar sobre os estudos que fazia aos meus alunos do curso de Pedagogia da USP, em um período em que o tema da diversidade começava a despontar no currículo e quase não havia material para consulta. Era sempre a mesma disposição que a animava: queria os negros e os indígenas como donos do saber que é capaz de tornar poderosos os homens e as mulheres.

Elba Siqueira de Sá Barretto (Pesquisadora FCC)

Convivi com Regina Pahim quase 15 anos, o tempo em que me encontro na Fundação Carlos Chagas, e sinto sua perda não apenas pelo afeto que Ihe dedicava, mas também porque Regina reunia qualidades que, em si, são cada vez mais raras.

Ao longo desse convívio profissional, em que sempre estivemos às voltas com os acertos de textos nas várias edições, pude admirar em Regina a dedicação amorosa ao trabalho e o seu esmero em busca de uma frase bem feita.

Conterrânea, do Norte Velho paranaense, Regina compreendia bem o que eu, fazendo uso de uma expressão supostamente caipira, dizia: "editar texto é arrancar tiririca, a gente limpa a roça e, sem que se espere, vem chuva, vem vento, vem passarinho, e lá está tiririca nascendo de novo". Este trabalho árduo e minucioso ela regia com paciência, alegria e afetuosidade incomuns aos que editam textos, e assim fazia a planta do pensamento viver forte.

Regina era uma mulher bonita, e tinha um jeito discreto de se apresentar; não usava enfeites ou artifícios. Era dona de um gosto apurado, amava a clareza e síntese no discurso e a música erudita. Foi embora suavemente, 
como uma folha verde escura que uma chuva inesperada, no início do outono, destaca de uma árvore.

Áurea Maria Corsi (Assistente editorial de Cadernos de Pesquisa)

Todas as vezes que encontrava Regina recebia dela um elogio, um carinho. Não chegamos a ter a oportunidade de trabalhar juntas, embora convivendo lado a lado, no mesmo ambiente, por tantos anos. Ainda assim, um respeito mútuo nos aproximava.

Sempre achei Regina brilhante e por isso mesmo eu nunca consegui entender a singeleza com que tratava sua expertise... trabalhando quietinha, sem alarde, em seu canto...

...ficará sempre a sensação de imensa perda...

Sandra Unbehaum

(Coordenadora do Departamento de Pesquisas Educacionais/FCC)

Em sua mensagem de pesar pela morte de Regina, Maria Helena dos Santos, ex-bolsista IFP, nos consolou com uma canção de Luiz Tatit que, de certo modo, traduz o sentimento de todos(as) nós que perdemos a Regina, pois, sempre que alguém daqui vai embora, dói bastante, mas depois melhora...

Fúlvia Rosemberg (Pesquisadora FCC, Coordenadora do IFP no Brasil) 